\title{
THIRD SECTOR ORGANISATIONS AND GOVERNANCE PROCESS
}

Jenny Onyx

\section{Introduction}

There appear to be several quite different discourses that may impact the governance processes of Asian third sector organisations. The first is the so called 'modern' approach: the Corporate Governance model derived from the corporate world of business. It refers to the capacity of the Board and management to drive the company forward within a framework of effective accountability (PricewaterhouseCoopers). Notice the use of the word "drive”. This word implies giving direction from above, but also a sense of forcing the organisation to maximise its production.

There are a number of assumptions in this notion of governance (Onyx, 2002). It assumes that the organisation is performing a set of actions on behalf of an external set of shareholders or stakeholders. Those stakeholders will judge the performance of the organisation by observable outcomes. The responsibilities of governance rest primarily with the Board. The Board must be independent of management and be comprised of people who are elected or appointed independently, ie not by government or the CEO. It is the task of the Board to set the mission of the organisation, and to determine the broad strategic direction that the organisation is to take. The manager is then accountable to the Board for the successful operationalisation of these strategic directions. The principle aim of management is to make the organisation more efficient and effective, in order to maximize its performance with minimal cost. The organisation is concerned with the achievement of specified objectives. The objectives are concrete, specific, practical targets established to achieve the organisations larger mission. It is the manager's task to make sure that the organisation meets its objectives (but not to set the mission). Work follows formal procedures and rules, all of which are documented in strategic plans, budgets, procedure manuals, job specifications, annual reports and so on. The work of the organisation is normally carried out by division in terms of specialisation of function (functional division) and hierarchy (ordered authority). The effectiveness of the manager rests with his authority. The manager obtains his position of authority by virtue of his 
skill and knowledge and demonstrated ability through competitive appointment. The manager does not own the property or product of the organisation.

While this model of corporate governance is generally regarded as the most appropriate and one that third sector organisations seek to emulate, a recent survey of American nonprofits found that only a minority of Boards were active in monitoring organisational programs and services (Ostrower, 2007). They were however, relatively more likely to set policy, maintain financial oversight, and evaluate the CEO.

A second and quite different model of governance in Asian Third sector organisations draws on traditional Asian perspectives. Here there is an emphasis on the values of respect for the elders and for tradition (Pye,1999). Social capital networks tend to form around kinship, common origin and especially around patron/ client relationships. Membership of the organisation is usually a given and does not change.

Within this model of governance, the leader obtains their position by traditional means. The leader of a kinship group for instance will normally be the eldest male of a particular lineage. The leader of a village women's group will normally be a senior respected woman, perhaps the wife of the headman. The leader of a religious group will normally also be the male who has reached a particular level of seniority, usually as appointed by an external authority. The position of patron is partly one of tradition, but also of wealth and power. There is not usually a democratic election of the leader, nor an independent process of advertisement and selection by merit.

Good governance in this case involves the responsible and ethical carriage of authority by the elder or patron. The purpose and direction of the organisation is usually a given; it is considered self evident, and is based on traditional values and assumptions. The leader will from time to time re-interpret those values and organisational purpose as circumstances demand, but will not be expected to create or change the "strategic direction" of the organisation. The members do not question the direction of the leader, but rather seek to contribute to maintaining internal harmony of the organisation. In 
return for their loyalty, the patron or leader is expected to support and protect the interests of the members. However all decisions will ultimately be determined by the elder or patron. Within the organisation, this leader is identified as "the driving force" (see also the Driving force model in Chapter 9).

There is not usually a direct form of accountability. The leader may be accountable to some higher form of authority such as God or the state. At the local level, he may be accountable in an implicit way to the consensus of his people. But there is usually no formal or written form of accountability. From a modern corporate perspective this approach to governance is less effective and open to abuse and potential corruption. However from a traditional Asian perspective, it rests on time honoured principles of personal integrity, tradition, and the preservation of social harmony.

A third model of governance is the Democratic Model. This may involve the election of Board members. But it is more likely to involve a form of participatory democracy. This requires a form of governance that involves the people, or members of the organisation in an open and participatory manner. The principles and practice of community development (McArdle, 1989, Kenny, 1994) can be articulated as:

- Decision making by those most affected by outcomes of the decision: the subsidiarity principle,

- Personal empowerment and control by individual citizens over their own life: the empowerment principle,

- The development of ongoing structures and processes by which groups can meet their own needs: the structural principle.

A democratic form of governance requires some form of consensus of equals and transparency of process. While it is often held as an ideal, the actual mechanisms by which decision making can genuinely occur in this way is much more difficult to achieve. The requirements of good governance concern the genuine participation of all stakeholders in decision making, including the setting of the organisational goals and strategic direction, a process of carrying out the decisions that is effective and 
empowering for the members, and a form of accountability that is open and visible to all. The emphasis at all levels is on inclusivity.

If the organisation is small enough, then it may be possible for all decisions to be made by consensus, as in the traditional collective. This may happen in small village organisations. However consensus becomes cumbersome and ineffective once the organisation becomes large and complex. Some sort of representative selection of core decision makers may be used, perhaps with broad principles being endorsed through general meetings. Key stakeholders may be represented on smaller committees or action groups.

The challenge of good governance within the participatory democratic model is to establish processes which genuinely empower the individual and which mobilize social capital itself. One of the key tasks of the co-ordinator or facilitator is the provision of appropriate information in a timely manner to provide the basis for effective decision making by the stakeholders involved. It is also necessary to recognize and mobilize local resources: financial resources but also local knowledge, trust, and the voluntary labour of their members. These resources are less visible but equally important to the collective enterprise.

The participatory democratic organisation must also develop appropriate methods of accountability. Bureaucratic forms of line accountability will not suffice. Accountability mechanisms need to be consistent with the principles of participatory democracy itself, that are transparent and open and understandable to all. Like social capital the mechanisms will foster trust, participation in networks and social agency. What is required is the accountability of transparency. This is a kind of communal accountability, not directed upwards to the controlling sponsor or patron, but a generalized accountability to all interested parties, including in particular the constituent community, and the organization's clients. 
All three models of governance provide appropriate features of "good governance" under specific circumstances. The question then concerns the appropriate form of governance for third sector organisations as opposed to those in the other sectors. And what is the appropriate form of governance in Asian third sector organisations? In this chapter we examine the governance processes used within Asian third sector organisations. Our data is drawn from the results of the Organizational questionnaire survey, which was completed by 492 Organizations over the six countries.

As far as possible the survey results and the organisational case studies will be examined from the perspective of the three models.

\section{Method of analysis}

A detailed account of the methodology for this organizational survey is provided in chapter one. However, it should be reminded that while the sample in each country was approached in a standardized way, and covers the broad variety of third sector organisations, nonetheless the overall samples cannot be considered fully representative, nor are the samples for each country directly comparable. No country was able to adequately assess the thousands of organizations located in small rural villages, or those which were not registered. In some cases, particularly in India, the case studies shed some light on organisational processes in these small organisations. But, we essentially have a sample of well established and officially recognized third sector organizations in six Asian countries. For those organizations we can build a picture of the way the organization says that it operates.

The statistical analysis makes use of SPSS package. Frequencies are determined for each question by country. In addition, several items of the questionnaire dealt with common themes of decision making, planning, financial management, accountability, and external relations. Within each of these topics, the data has been reduced to form coherent scales following a factor analysis, using principle component analysis and varimax rotation. This created a total of 10 separate scales. Within each scale, each identified item was scored as one. The higher the number of activities identified as being 
undertaken by the organisation, the higher the score. The scale scores were then standardised so that the score on each scale had a minimum of zero and a maximum score or 10 .

The scales were then examined for their relationship to the key independent variables of incorporation or registration with government, the presence of a membership base, presence of paid staff, the receipt of government, domestic or foreign funding. This is done for each scale using multivariate analysis of variance and/or multiple linear regression equations.

\section{Decision Making}

A key question of any organisation concerns how decisions are made and by whom. Comparative data is available that provides some answers to these questions for Asian third sector organisations. Table 6.1 summarizes this data.

[Insert table 6.1 about here]

Of those surveyed, $87 \%$ of all organizations had some sort of management committee or board. This varied from a low of 63\% for Indonesia to a high of $98 \%$ for India. Board or committee meetings were held regularly with a mean number of board meetings per year of 6.9 (median of 4). This suggests that on average, most board/ committees met every two months. However this figure belies tremendous variation by country. In China, 37\% of organisations met only once a year, while a further 31\% met two or three times a year.

Board members were involved in regular meetings, but were often also required to provide professional advice; 83\% overall did so. For board meetings an agenda is generally available before the meeting in $80 \%$ of cases, (less often in Indonesia and more often in the Philippines). Decisions within Board meetings are made by consensus rather than voting in $72 \%$ of organisations. In $84 \%$ of cases, minutes of the meeting are taken. 
General meetings, that is ones involving the whole membership, are held by $70 \%$ of the organisations, with a low of 58\% in China and a high of 84\% in Philippines and Thailand. For those with general meetings, the number of general meetings a year ranges from a mean of 1.3 for India, Philippines and Thailand to a mean of 3.3 for China and 7.3 for Vietnam (where they take the place of Board meetings). General meetings are open to the public as well as to members in $39 \%$ of the time. There are very large national differences here, with a low of 9\% for China, 22\% for Vietnam, 29\% for Indonesia, 42\% for Philippines, 51\% for Thailand and a high of $60 \%$ for India. Decisions made at general meetings are by consensus rather than voting in $53 \%$ of cases with a low of $40 \%$ for China to a high of $64 \%$ in Thailand. A written record of the general meeting is taken in $68 \%$ of cases.

The presence of these mechanisms of "good practice" are highest in India and Philippines which have largely maintained a democratic government since independence. The corporate governance model requires active involvement of the Board, but not necessarily open general meetings. Those with regular General meetings are more likely to occur within the democratic model of governance. These are generally open to all members, but are much less likely to be open to the public anywhere. China and Vietnam are least open in terms of their decision making mechanisms.

Many organisations across all countries acknowledged the importance of a "driving force". That is, a single powerful person is seen to drive the organisation. Overall, approximately 65\% identified a "driving force". This person is likely to be the founder (33\%) and/or the CEO (28\%) or chairperson. (25\%). However this person did not necessarily have the final say; in less than $20 \%$ of organisations was this the case. The presence of a "driving force" suggests that even where a Board exists, the patron/ client model of governance dominates. This is confirmed in several of the country reports (India, Indonesia, Thailand, Philippines). (See Chapter 11 for more discussion).

The form of decision making is heavily influenced by a number of internal and external factors, notably whether or not the organization is incorporated or registered with 
government, whether or not it receives external funding of various kinds, whether or not it has a membership base, and whether or not it has paid staff. These results are summarized in tables 6.2, 6.3 and 6.4. Most of these effects are significant at the .000 level, indicating that they have not occurred by chance.

[Insert tables 6.2, 6.3, and 6.5 about here]

Organizations are far more likely to maintain formal decision making processes if they are incorporated (being registered has the same effect). Receiving foreign funding, or government funding also makes a huge difference to the way in which the Board functions but seems to have little effect on General Meetings. The presence of paid staff also makes a difference to the formal decision making processes. As we might expect, organizations are much more likely to engage in formal decision making processes if paid staff are available to assist with these tasks, as indicated in table 6.4.

On the other hand, the presence of a membership base becomes significant in relation to General Meetings. Having members makes little difference to the functioning of the board; in fact if members were present, board members were less likely to provide professional advice. But membership makes it more likely that General Meetings are held (76\%vs 64\%, $\mathrm{p}<.005$ ), and that they are open to the public (40\%vs $29 \%, \mathrm{p}<.01$ ). Again this suggests that in these cases the democratic governance model is more likely to be in operation.

In summary, the majority of organisations that are incorporated, registered with government, that receive foreign or government funding and have paid staff, have well defined formal decision making processes involving regular board meetings and an annual general meeting. There are important regional variations. In general India, Philippines and Thailand conform most closely to the northern corporate governance model of decision making. It is hard to identify why this is so. In part it may be a sampling error. But both India and Philippines have developed mature third sector/ state relationships, with strong influences from British/ American institutions. China and 
Vietnam have only recently begun to form such structures. It is interesting to note that the presence of foreign funding appears to require a formal Board structure, but does not require a membership base or General Meeting such as an AGM.

\section{Small, traditional, Unincorporated organisations:}

It is very difficult to make any definitive statement from the quantitative data concerning traditional organisations, except that they appear to be in the minority of this sample of Asian third sector organisations. Those organisations with members, and no foreign funding are less likely to follow the corporate decision making model. While there is little evidence from the survey data concerning the more usual decision making practice among traditional Asian organizations, there is some indirect evidence here, and some evidence from the case studies. Those with a membership base are much more likely to hold General meetings, open to the public. In addition, the majority of all organizations clearly preferred a consensus model of decision making rather than voting, both for Board decisions (72\%) and General Meetings (53\%). This pattern is consistent both for the traditional (driving force) model and for the democratic model, but not for the corporate model where the Board is expected to take a monitoring role.

We do know that those organizations that are incorporated or receive foreign funding are in fact the minority of Asian third sector organizations. For example a survey of third sector organizations in India in 2000 found that there were about 1.2 million organisations, almost half of which were unregistered (Sribastava and Tandon, 2005). Many of these are small, rural organizations, about which little is known. However, as part of the current study, a small group of 14 case studies were undertaken (Dongre et al, 2006). The study notes in part:

The 14 Third sector organisations without formal board are either membership based or community based organisations. They generally design a fixed programme on a collective basis on the activity to be taken up during the year. Among these organisations, those having law and advocacy as part of their activity other than the identified tasks, will address the issues as and when they 
emerge. These TSOs have a ....collective decision-making and execution system. No single individual is important here. All decisions are taken collectively in the presence of members/ or target group. Then based on the task to be undertaken, a group of representatives will be selected to execute the work, These groups are in charge for a year. Each year the groups change by rotation. ...The members attend the weekly meetings very religiously. A smaller group is formed to take decisions during emergencies when a meeting could not be convened or the other members could not be reached. ( Dongre et al, 2006, p9)

In the case of these informal organisations, the majority have a detailed form of documentation of the activities of the organisation, including the results of the general meetings. These can be in both oral and written form. Some use only oral documentation; this may be in the form of songs which are created in the meeting and sung by all members at the end of the presentation, and then passed on to others in the community.

A second example of informal organisations comes from Indonesia (Radyati, 2006). Here there are an unknown but very large number of arisan groups. These are unregistered and do not have a Board or other governing body apart from an elected chair and treasurer. An arisan is a group of people or families who know each other well, often for example coming from the same village (now living in an urban context), who meet regularly to form a kind of traditional micro-credit or savings scheme. Each month all contribute an agreed sum of money and the members draw lots in order to determine who may receive the total sum for that period. In many cases, especially in urban settings, the main purpose of the arisan has shifted to include a social objective, to maintain ongoing social bonds. The running of the organisation is based on trust. All members have a commitment to attend and contribute at all meetings until the round is finished and all members have had a turn to win. Decisions (such as amount of contribution, place of meeting) are made through open discussion and consensus. The chair has a co-ordinating role only, while the treasurer collects the money.

\section{Planning}


Planning is a special case of decision making. The summary survey results are provided in Table 6.5 and 6.6. A formal planning process was undertaken by $95 \%$ of third sector organisations across the region (there were no significant differences between countries; only Thailand recorded a lower rate of 86\%). In the combined sample from all countries, $87 \%$ of organisations have a mission statement (somewhat less in Thailand and more in Philippines). Overall, 91\% of organisations have written objectives (somewhat less in India and more in Philippines). Ninety three percent prepare plans before initiating major projects (no significant difference between countries). Written proposals are circulated to members before the board meeting in $71 \%$ of organisations overall, ranging from a low of $46 \%$ in Indonesia to a high of $90 \%$ in Vietnam. These items combine to form a Planning scale (Planning A). Organisations with a higher score for Planning A are more likely to be registered with government, but not more likely to be incorporated. There is little difference on this dimension for membership, paid staff, or foreign funding.

[Insert table 6.5 about here]

The other aspect of planning concerns the development of a strategic/business plan. The items concerning this aspect also combine to form a scale (Planning B). The overall results are summarized in Table 6.6. Most (67\%) of organisations involve the Board in succession plans for the CEO and/or Board members (less in China and more in India). Even more (83\% of organisations) prepare a strategic/ business plan (less in Thailand and Indonesia, and more in Philippines and Vietnam. This strategic/ business plan is reviewed on a regular basis in $76 \%$ of cases overall. The Board is involved in the development of the strategic/business plan in $69 \%$ of cases (from a low of $47 \%$ in Indonesia to a high of $86 \%$ in Philippines and Vietnam). The Board has to approve the strategic/business plan in $70 \%$ of cases overall (from a low of $45 \%$ in Indonesia to a high of $83 \%$ in Vietnam). The Board is involved in a review of the strategic/business plan in 65\% of cases (from a low of $47 \%$ in Indonesia to a high of $89 \%$ in Philippines). This strategic/ business plan is available to members/ constituents in $63 \%$ of cases (from a low of $53 \%$ in Indonesia and in Thailand to a high of $79 \%$ in Philippines and 83\% in Vietnam. Strategic planning is generally considered an important mark of best corporate model practice. There are strong regional differences among the Asian organisations sampled, with strong evidence 
of strategic planning in Vietnam, and Philippines, but less evidence in Indonesia and Thailand.

[table 6.6 about here]

These items relating to the strategic/business plan (including succession planning) together form a planning scale, Planning B. This kind of planning is strongly influenced by a number of variables, as indicated in the linear regression of Table 6.7. These include being registered, having members, receiving foreign funding and having paid staff.

[table 6.7 about here]

In summary, while nearly all third sector organisations (95\%) are likely to engage in some sort of planning, regardless of their funding source and incorporation status, not all engage in a formal strategic planning procedure. Those that do so (about $70 \%$ overall) are more likely to be incorporated and registered, to have a membership base and paid staff, and foreign funding. We know little about the planning process in non-incorporated, traditional organizations. However, the case study material suggests that the collective process entails the collective development of the mission of the organisations, and specific events requiring advocacy action are thoroughly discussed by the full membership before a collective plan of action emerges, usually with one or more spokespersons/ action groups also identified as part of the plan (Dongre et al., 2006).

\section{Financial Management}

Most organizations have a formal financial management procedure (see Table 6.8). A formal financial procedure is followed by $93 \%$ of organizations across the region, with no significant variation by country. Overall, $82 \%$ of organizations prepare a budget, less so in Vietnam and China, but more so in India and Philippines. Somewhat fewer produce monthly cash flow budgets: $74 \%$ overall, ranging from $42 \%$ in China to $87 \%$ in Philippines. Most organisations in all countries produce annual financial statements, less so in Vietnam and China, more so in Philippines and India. Eighty one percent of organizations have an asset register, with similar regional variations. 
These items together form the scale Financial Management A (see Table 6.9). This scale discriminates organizations according to whether or not they are incorporated (those incorporated score higher). Whether or not the organization has members makes no difference to their financial management, but the presence of paid staff makes the organization significantly more likely to have financial Management procedures in place. The presence of foreign funding similarly makes it more likely that the organization will have financial Management procedures in place.

[insert table 6.9 about here]

The Financial Management scale provides reasonably strong evidence that those organisations which accept foreign funding and are incorporated will adopt some part of the corporate governance model, at least in terms of financial management practices. Those organisations that are least likely to adopt conventional financial management practices are those in Vietnam and China, where a strong communist state appears to adopt a different tradition of financial control.

Once again, we have little direct evidence of financial management among traditional groups. We do know, for example, among small, grass roots, micro-credit organisations such as the Indonesian arisan, that financial planning and disclosure involves the whole group on a consensual basis. Here money is paid and distributed each meeting, before the whole group, as part of the days proceedings, usually before the social part of the day which is likely to entail shared food.

\section{Stakeholder Relations}

Stakeholder relations include a number of functions. Part of it relates to accountability functions and the extent to which reports are made to various stakeholders (see next chapter). But stakeholder relations also include negotiations for external funding, as well as networking with other organizations and other advocacy activities. As indicated in Table $6.10,60 \%$ of organizations prepare funding submissions to government and/or other funding bodies. India (79\%) and Thailand (76\%) are most likely to do so, while 
Vietnam (37\%) is least likely to do so. Coordination with other third sector organisations providing similar services occurs in $78 \%$ of cases overall, with a low of $46 \%$ reported in Vietnam, up to 95\% reported in the Philippines. Across the region 64\% of third sector organisations claim to make representations to government on matters other than funding, with a low of 38\% for Vietnam, 48\% in Indonesia, to a high of $90 \%$ in Philippines.

[Insert table 6.10 about here]

The role of the Board is a vital clue to the overall governance of Asian Third Sector organisations. Overall, only 44\% of Boards are involved in the preparation of submissions to funding bodies (less in Indonesia, more in Thailand). Overall, a slightly larger proportion (51\%) of Boards approves such submissions (low of 25\% in Indonesia to a high of $72 \%$ in India). Across the region, $46 \%$ of Boards get involved in making representations to funding bodies (30\% in Indonesia to 64\% in Thailand). Overall $49 \%$ of organisations claim that board members seek donations from friends and acquaintances, ranging from 36\% in Vietnam, to 60\% in Thailand. Fifty-four percent of organisations claim that board members help negotiate around the political system on behalf of the organisation. This varies from a low of $37 \%$ in Indonesia to a high of $77 \%$ in Thailand. In general it appears that Board members are involved in public relations, including seeking funds, in about half the organisations questioned. By extrapolation, we may assume that such functions are carried out by paid staff in a further $20 \%$ of cases, and not carried out at all in the remainder (30\%). This compares for instance with only $29 \%$ of Boards in the United States which claim to be very active in fund raising, (and 35\% were not involved at all). Similarly, among U.S. nonprofits, some $70 \%$ had no involvement in public policy and 30\% had no involvement in community relations (Ostrower, 2007). This would suggest that many Asian Boards are in fact MORE involved in the actual work of the organisation than are American nonprofits.

Organizations may also communicate to a broader constituency by means of a regular newsletter or website. As indicated in Table 6.9, 48\% produce a regular newsletter, and $44 \%$ of organisations have a website. The external relations items clustered into three scales. The first, external relations A, includes five items dealing with having a formal 
mechanism for reporting, especially annual report, coordinating with other organisations and advocacy functions. The second scale, external relations B, comprises those five items dealing with Board/committee involvement in external relations. The third scale, external relations C, identifies organisations having a regular newsletter or website. These scales are further discussed in the following chapter on Accountability.

\section{Re-inserting Cultural Values}

We did not ask about the cultural values within which each organisation operated. However the researchers within each country reported orally that the obtained data should only be interpreted within the cultural values. That is, while the outward form of the organisation may resemble the corporate model, the actual way in which they operated was likely to be quite different. Perhaps the most informative example of this came from Thailand in which most organisations indeed conformed to the corporate model, but where for example, one organisation had a mythical spiritual entity as chair of the Board. In Thailand, governance has traditionally evolved from an absolute monarchy, now a constitutional monarchy. Within this system, the monarch, and indeed any patron or person in power, is expected to abide by the ten principles, based largely on Buddhism (Vichit-Vadakan et al, 2005). These principles include, for example, the values of generosity, integrity, non-violence, and non-oppression. Most third sector organisations

are governed by a “driving force” or patron, in a patron-client relationship, regardless of the formal structure of the organisation. However, the level of loyalty and commitment by organisational members and employees will depend largely on the extent to which the patron abides by the ten principles.

We also know from the country report from Philippines, that the distinction between management and governance (from the Board) should be treated with caution:

This response should be appreciated within the context of Filipino values, particularly the importance of social acceptance among Filipinos. These are manifested in the values of hiya (embarrassment, shame), tayo-tayo (we are one family), utang na loob(debt of gratitude), paggaoang sa nakatatanda (respect for elders), Pakiramdaman (being sensitive to the feelings of others) and pakikisama 
(being agreeable and yielding to others; being a team player). The objective of these is to maintain SIR (smooth interpersonal relations) and avoid disagreement. (Domingo, 2005).

What this reminds us of is the importance of building or maintaining social capital. The Filipino values are central to maintaining harmony within close knit communities, of building the trust and mutually supportive networks that not only support the mission of the organisation, but help to weave wider patterns of collaborative relations within the community. In that context it is regarded as a major crisis of trust for the Board or any of its members openly challenged the leadership of the organisation.

Most countries in South East Asia, and particularly Indonesia and Thailand have very similar cultural values. It therefore might be expected that where there is a Board that is separate from the staff and volunteers of the organisation, that every attempt will be made to ensure that there is a harmony of consensus over all operating and strategic matters. Under such circumstances, it is unlikely that the Board is able to determine the direction of the organisation, or to call to account the actions of those within it. What is less clear is the extent to which decisions and actions made within the organisation are transparent to all stakeholders. It does appear that where the elders are trusted to make decisions for all, there is little expectation that proceedings be open to scrutiny by members or the general public.

It would be interesting, and I think crucial, to compare the kind of results we obtained in this survey, with a similar examination of the organizational practices of small, grass roots organisations, particularly those operating at village level. Again, the literature suggests that these organisations (such as traditional irrigation management groups), by their nature, are totally transparent and democratic in their operations. Formal records and accounts may be rudimentary, but all households are represented in decision making, meetings are public and financial transactions visible. We know less about the governance of religious organisations such as Mosques, Temples and Churches, which are likely to be governed according to their own traditional rules designed to safeguard the integrity of the religious community. 
What we can conclude from this first comparative survey of Asian third sector organisations is that those which are most visible to the international community, and which have a reputation for being high performing, do indeed begin to approximate the organisational corporate governance practices that are the benchmark of most western organisations, particularly in terms of governance Board structure and financial management practices. This is less likely in the communist traditions of Vietnam and China. However, even those organisations that most appear to follow a corporate governance model, as in Philippines, may do so in form only, and to the extent that that form can operate within traditional values of smooth interpersonal relations.

There are advantages to each model of governance. The corporate model of governance enables maximum flexibility and control over the direction of the organisation by a small group of people, and by the external funding body. It also provides a legal form and accountability mechanism, which minimizes the possibility of corruption. But it does not guarantee freedom from abuse. Indeed we can all tell tales of scandal and corruption that have involved the biggest third sector organisations including those which have adopted the corporate model of governance, both in Asia and in the United States itself.

However, the corporate model of management is not conducive to the development of social capital, or to the maximum empowerment of individuals within civil society. Those that seek to frame their organisation around the values of trust, empowerment, and the development of a stronger civil society, need to consider forms of governance that go beyond the corporate model. One option is to retain, or to return to the traditional model. The traditional model of governance may have been reasonably effective in mobilizing social capital at the local level, and for some purposes, this may still be the appropriate model. Change is not always useful. However the traditional model is unlikely to work over time at the national level, although it may have a role to play in the mobilizing of 'people power' in the short term. And the values of respect and civility are important in maintaining a national consensus. 
The most effective model of governance for the purposes of developing social capital and a strong civil society is the model of community development, or the participatory democratic model. This is the model most likely to occur in small, local, traditional, grass-roots organisations across Asia. However, we have little direct evidence concerning the governance of these forms of organisation, or the effectiveness of their decision making processes. While we have gained considerable knowledge of some governance issues in Asian Third Sector organisations, there remains much to learn.

\section{References}

Dongre, Y., Gopalan, S., Rajeev, I., Sreevalli, A. (2006) Third Sector Governance: A Study of Decision Making Process among the Non-Formal TSOs. $7^{\text {th }}$ International ISTR Conference, Bangkok.

Kenny, S. (1994) Developing Communities for the Future: Community Development in Australia. Thomas Nelson, Melbourne

McArdle, J. (1989) Community Development: Tools of the trade. Community Quarterly $16,47-54$

Onyx, J. (2002) Third Sector Governance and its Contribution to Civil Society. International conference on "Public Administration plus Governance: Assessing the Past, Addressing the Future” Manila.

Ostrower, F. (2007) Nonprofit governance in the United States: findings on Performance and Accountability from the First National Representative Study. The Urban Institute. Centre on Nonprofits and Philanthropy.

Pye, L. (1999) Civility, social capital and civil society: three powerful concepts for explaining Asia. The Journal of Interdisciplinary History, 29, 4, 763-773.

Srivastava, S., and Tandon, R. (2002) Exploring the Nonprofit sector in India The John Hopkins University Institute for Policy Studies. 

Table 6.1: Decision Making

\begin{tabular}{|l|l|}
\hline Organisation has a Board & $87 \%$ \\
\hline Board meets on a regular basis & $80 \%$ \\
\hline Agenda Available before meeting & $80 \%$ \\
\hline Organisation holds general meetings & $70 \%$ \\
\hline General meetings open to the public & $39 \%$ \\
\hline
\end{tabular}


Table 6.2: Influences on Decision Making: Incorporation

\begin{tabular}{|c|c|c|c|}
\hline Item & Presence & Absence & Significance \\
\hline Has Board & $94 \%$ & $51 \%$ & .000 \\
\hline $\begin{array}{c}\text { Board meets } \\
\text { regularly }\end{array}$ & $88 \%$ & $44 \%$ & .000 \\
\hline $\begin{array}{c}\text { Professional } \\
\text { Advice }\end{array}$ & $86 \%$ & $45 \%$ & .000 \\
\hline $\begin{array}{c}\text { Agenda } \\
\text { Available }\end{array}$ & $86 \%$ & $45 \%$ & .000 \\
\hline $\begin{array}{c}\text { Minutes } \\
\text { Taken }\end{array}$ & $90 \%$ & $46 \%$ & .000 \\
\hline $\begin{array}{c}\text { General } \\
\text { Meetings }\end{array}$ & $78 \%$ & $42 \%$ & .000 \\
\hline $\begin{array}{c}\text { GM Open to } \\
\text { Public }\end{array}$ & $39 \%$ & $21 \%$ & .000 \\
\hline $\begin{array}{c}\text { Written record } \\
\text { for GM }\end{array}$ & $74 \%$ & $38 \%$ & .000 \\
\hline
\end{tabular}


Table 6.3: Influences on Decision Making: Foreign Funding

\begin{tabular}{|c|c|c|c|}
\hline Item & Presence & Absence & Significance \\
\hline Has a Board & $92 \%$ & $80 \%$ & .000 \\
\hline $\begin{array}{c}\text { Board Meets } \\
\text { Regularly }\end{array}$ & $88 \%$ & $70 \%$ & .000 \\
\hline Professional Advice & $89 \%$ & $66 \%$ & .000 \\
\hline Agenda Available & $86 \%$ & $71 \%$ & .000 \\
\hline Minutes Taken & $90 \%$ & $73 \%$ & .000 \\
\hline General Meetings & & & Ns \\
\hline GM open to public & & & Ns \\
\hline Written record for & & & \\
GM & & & \\
\hline
\end{tabular}


Table 6.4: Influences on decision making: Paid Staff

\begin{tabular}{|c|c|c|c|}
\hline Item & Presence & Absence & Significance \\
\hline $\begin{array}{c}\text { Board Meets } \\
\text { regularly }\end{array}$ & $88 \%$ & $60 \%$ & .000 \\
\hline Professional Advice & $84 \%$ & $63 \%$ & .000 \\
\hline Agenda Available & $86 \%$ & $61 \%$ & .000 \\
\hline Minutes taken & $89 \%$ & $65 \%$ & .000 \\
\hline General Meetings & $76 \%$ & $60 \%$ & .000 \\
\hline GM open to public & & & ns \\
\hline $\begin{array}{c}\text { Written record of } \\
\text { GM }\end{array}$ & $73 \%$ & $55 \%$ & .000 \\
\hline
\end{tabular}


Table 6.5: Planning A

\begin{tabular}{|l|l|}
\hline Has formal planning process & $95 \%$ \\
\hline Has a mission statement & $87 \%$ \\
\hline Has written objectives & $91 \%$ \\
\hline $\begin{array}{l}\text { Prepares plans before initiating major } \\
\text { project }\end{array}$ & $93 \%$ \\
\hline Proposals circulated to members & $71 \%$ \\
\hline
\end{tabular}


Table 6.6: Planning B

\begin{tabular}{|l|l|}
\hline $\begin{array}{l}\text { Board involved in succession plans for } \\
\text { CEO and/or Board members }\end{array}$ & $67 \%$ \\
\hline Has strategic/Business plan & $83 \%$ \\
\hline Plan reviewed on a regular basis & $76 \%$ \\
\hline Board involved in development of plan & $69 \%$ \\
\hline Board approves plan & $70 \%$ \\
\hline Board involved in review of plan & $65 \%$ \\
\hline Plan available to members/constituents & $63 \%$ \\
\hline
\end{tabular}


Table 6.7

Independent variables significantly associated with Planning B score

\begin{tabular}{lrr}
\hline Variable & Coefficient & P-value \\
\hline Constant & 2.5 & - \\
Registered & 1.0 & 0.005 \\
Has members & 1.5 & 0.000 \\
Receives foreign funding & 0.9 & 0.003 \\
Incorporated & 2.0 & 0.000 \\
Paid staff & 1.1 & 0.004 \\
\hline \multicolumn{2}{c}{}
\end{tabular}


Table 6.8: Financial Management A

Financial Management A:

\begin{tabular}{|l|l|}
\hline Org has formal financial procedure & $93 \%$ \\
\hline Org prepares annual budget & $82 \%$ \\
\hline Org prepares monthly cash flow budget & $74 \%$ \\
\hline Annual financial statements & $88 \%$ \\
\hline Org has asset register & $81 \%$ \\
\hline
\end{tabular}


Table 6.9

Independent variables significantly associated with Financial Management A score

\begin{tabular}{|c|c|c|}
\hline Variable & Coefficient & P-value \\
\hline Constant & 5.4 & - \\
\hline Incorporated & 1.1 & 0.001 \\
\hline Paid staff & 2.0 & 0.000 \\
\hline Receives foreign funding & 0.9 & 0.000 \\
\hline
\end{tabular}

$\mathrm{R}^{2}=22.1 \%$ 
Table 6.10: Stakeholder Relations

\begin{tabular}{|c|c|}
\hline Prepares submissions for funding & $60 \%$ \\
\hline Coordination with other organizations & $78 \%$ \\
\hline Makes representations to government & $64 \%$ \\
\hline Board involved in submission & $44 \%$ \\
\hline Board involved in representation & $46 \%$ \\
\hline Board seeks donations & $49 \%$ \\
\hline Board helps negotiate system & $54 \%$ \\
\hline Org has regular newsletter & $48 \%$ \\
\hline Org has website & $44 \%$ \\
\hline
\end{tabular}

